\title{
Efficacy and safety of long-acting $\beta$-agonist/ long-acting muscarinic antagonist combinations in COPD: a network meta-analysis
}

\author{
Yuji Oba, ${ }^{1}$ Siva T Sarva, ${ }^{1}$ Sofia Dias ${ }^{2}$
}

- Additional material is available. To view please visit the journal online (http://dx. doi.org/10.1136/thoraxjnl2014-206732).

1 Division of Pulmonary, Critical Care and Environmental Medicine, University of Missouri, School of Medicine, Columbia, USA

${ }^{2}$ School of Social and Community Medicine, University of Bristol, Bristol, UK

\section{Correspondence to} Dr Yuji Oba, Division of Pulmonary, Critical Care and Environmental Medicine, University of Missouri,

School of Medicine, One Hospital Drive, CE 412 Columbia, MO 65212, USA obay@health.missouri.edu

Received 22 December 2014 Revised 28 August 2015 Accepted 27 September 2015 Published Online First 21 October 2015

\section{CrossMark}

To cite: Oba $Y$, Sarva ST Dias S. Thorax 2016;71:1525.

\section{ABSTRACT \\ Background The place of long-acting $\beta$ agonist/long-} acting muscarinic antagonist (LABA/LAMA) combinations in stable patients with COPD is not well defined. The purpose of this study was to systematically review the efficacy and safety of LABA/LAMA combinations. Methods Several databases and manufacturers' websites were searched for relevant clinical trials. Randomised control trials, at least 12 weeks duration, comparing a LABA/LAMA combination with placebo and/or monotherapy were included. The data were pooled using a network as well as a traditional direct comparison meta-analysis.

Results Twenty-three trials with a total of 27172 patients were included in the analysis. LABA/LAMA combinations were associated with a greater improvement in lung function, St. George's Respiratory Questionnaire (SGRQ) score, and Transitional Dyspnoea Index (TDI) than monotherapies. LABA/LAMA combinations were associated with a significantly greater proportion of SGRQ and TDI responders than monotherapies (OR 1.23 (95\% credible interval ( $\mathrm{Crl}$ ) 1.06-1.39), OR 1.34 (95\% Crl 1.19-1.50) versus LABAs and OR 1.24 (95\% Crl 1.11-1.36), OR 1.31 (95\% Crl 1.18-1.46) versus LAMAs, respectively) and fewer moderate-to-severe exacerbations compared with LABAs (HR 0.82 (95\% Crl 0.73-0.93)), but not when compared with LAMAs (HR 0.92 (95\% Crl 0.84-1.00)). There were no statistically significant differences associated with LABA/LAMA combinations compared with monotherapies in safety outcomes as well as in severe exacerbations.

Conclusions The combination therapy was the most effective strategy in improving lung function, quality of life, symptom scores and moderate-to-severe exacerbation rates, and had similar effects on safety outcomes and severe exacerbations as compared with monotherapies.

\section{INTRODUCTION}

COPD will likely become the third leading cause of death by 2030 according to WHO and continues to be a major cause of disability and rising healthcare costs worldwide. ${ }^{1}$ The total cost of COPD in 2010 was $\$ 49.9$ billion, including healthcare expenditures of $\$ 29.5$ billion in direct healthcare costs, $\$ 8.0$ billion in indirect morbidity costs and $\$ 12.4$ billion in indirect mortality costs in the USA. $^{2}$ These costs were the highest among common lung diseases.

\section{Key messages}

What is the key question?

- Do greater improvements of lung function with long-acting $\beta$ agonist/long-acting muscarinic antagonist (LABA/LAMA) combinations translate into better clinical benefits compared with monotherapies in stable patients with COPD?

\section{What is the bottom line?}

- The combination therapy was the most effective strategy in improving lung function, quality of life, symptom scores and moderate-to-severe exacerbation rates, and had similar effects on safety outcomes and severe exacerbations as compared with monotherapies.

\section{Why read on?}

- Our systematic review summarises the efficacy and safety of LABA/LAMA combination therapy in patients with moderate-to-severe COPD and describes the limitations of the current data.

Current guidelines developed by Global Initiative for COPD (GOLD) recommend a maintenance therapy either with a long-acting muscarinic antagonist (LAMA) or a long-acting $\beta$ agonist (LABA) in symptomatic patients with moderate or more severe COPD. ${ }^{3}$ When patients are not adequately controlled with a single long-acting bronchodilator, combining a LAMA with a LABA may be beneficial. $^{4}$

European and Japanese regulatory agencies recently approved a once-daily fixed-dose combination of indacaterol and glycopyrronium as a maintenance bronchodilator treatment to relieve symptoms in adult patients with COPD. A fixeddose combination of umeclidinium/vilanterol was approved in the USA and Canada for maintenance treatment of COPD. ${ }^{5}$ Although LABA/LAMA combination therapies were superior to monotherapies with regards to lung function improvement, it is less clear that the surplus of bronchodilation by combination therapy would translate into better clinical outcomes such as better quality of life and fewer exacerbations. ${ }^{67}$

The purpose of this study was to systematically review the efficacy and safety of LABA/LAMA 
combinations in COPD from randomised controlled trials with a network meta-analysis (NMA) as well as with a traditional direct comparison meta-analysis. When no clinical trials exist that directly compare all relevant treatment options, indirect comparisons can be made by comparing the relative effects of treatments against a common comparator or combining a variety of comparisons that taken together from one or more chains linking the treatments of interest (variously referred to as a multiple treatment comparison or NMA). ${ }^{8}$

\section{METHODS}

\section{Identification of trials and data extraction}

We identified all relevant clinical trials which evaluated clinical efficacies and safety of a LABA/LAMA combination in stable patients with COPD without an acute or recent exacerbation. Two authors (YO, STS) independently searched the Ovid Medline database for studies published from 1946 to 21 May 2015 using the MeSH headings and keywords: randomised controlled trial AND Pulmonary Disease, Chronic Obstructive AND aclidinium, glycopyrronium, or tiotropium AND formoterol, indacaterol, olodaterol, salmeterol, or vilanterol OR QVA149. In addition, we searched Scopus, CINAHL and the internet including the online trial registries of manufacturers of the above mentioned fixed-dose LABA/LAMA products. Bibliographies of all selected articles and review articles which included information on a LABA/LAMA combination in COPD were also reviewed for other relevant articles. We included any randomised clinical trial, published or unpublished, evaluating patients with COPD with a LABA/LAMA combination. Randomised control trials had to be of at least 12 weeks duration. A control intervention had to include a placebo, a LABA or a LAMA. We chose change from baseline (CFB) in trough $\mathrm{FEV}_{1}$ in litres, Transitional Dyspnoea Index (TDI), CFB in St. George's Respiratory Questionnaire (SGRQ), a proportion of SGRQ and TDI responders (defined as a subject with an improvement of at least 4 units in SGRQ total score or 1 unit in TDI score), ${ }^{9}$ COPD exacerbations, mortality, total serious adverse events (SAEs), cardiac SAEs and dropouts due to adverse event, as the outcome assessment criteria for the purpose of our meta-analysis.

Two authors (YO, STS) independently screened studies by title and abstract to evaluate whether a trial met the inclusion criteria. We extracted data on COPD exacerbations as moderate and severe. Moderate was generally defined as 'worsening respiratory status which required treatment with systemic corticosteroids and/or antibiotics' and severe as 'rapid deterioration which required hospitalisation'. Data were abstracted on study design, study size, population severity of illness, and the impact of a LABA/LAMA combination on the end points of interest. The risk of bias was assessed with the following items: (1) adequacy of sequence generation, (2) allocation concealment, (3) blinding of participants and investigators, (4) blinding of outcome assessment, (5) incomplete outcome data, (6) selective outcome reporting and other bias. ${ }^{10}$ Disagreements regarding values or analyses were resolved by discussion.

\section{Statistical analysis}

The primary analyses were NMAs using a Bayesian Markov chain Monte Carlo (MCMC) method and fitted in WinBUGS V.1.4.3 (Medical Research Council Biostatistics Unit, Cambridge, UK) using code adapted from Dias et al, ${ }^{11}$ which correctly accounts for correlations in trials with more than two arms. In a Bayesian analysis, a prior distribution of a parameter is the probability distribution that represents uncertainty about the parameter before the current data are examined. Current data and assumptions concerning how they were generated are summarised in the likelihood. Combining the prior distribution and the likelihood functions leads to the posterior distribution of the parameter which is used for inference. This distribution will be summarised by its median and $95 \%$ credible interval (CrI). Crls are the Bayesian equivalent of classical CIs, but they are interpreted as defining the probability (usually 95\%) that the relative treatment effects lie between its bounds. NMA estimates the comparative efficacy between all treatments, including those that have not been directly compared by including all relevant evidence (direct and indirect), and provide the most flexible approach to indirect comparison modelling. For the analyses in WinBUGS, inference was based on 100000 iterations of MCMC with an initial burn-in period of 50000 iterations. $^{12}$

A data structure table was constructed to choose an optimal model for each outcome (see online supplementary table S1). Model selection and its rationale are summarised in the online supplementary table S2. Each pair of treatments was compared by estimating an OR or HR for a dichotomous outcome and a difference in mean or median for a continuous outcome. Treatment baselines and effects were given vague normal priors with mean 0 and variance 10000 and between-trials SDs were given uniform distribution with lower bound 0 and upper bound 5 . The upper bound of 5 was thought to be sufficiently large for outcomes on a log scale. The posterior distribution was examined to ensure it was sufficiently different from the prior and that the prior was therefore not having undue influence on the resulting posterior.

The probability that each intervention arm was associated with being the most efficacious was calculated by counting the proportion of iterations of the Markov chain in which each intervention arm had the highest HR, OR or mean difference (MD). The surface under the cumulative ranking (SUCRA), which is a simple numerical summary of these probabilities, was also calculated. The SUCRA would be $100 \%$ when a treatment is certain to be the best and $0 \%$ when a treatment is certain to be the worst. ${ }^{13}$

Assessment of model fit was based on comparison of residual deviance to the number of unconstrained data points, and between-study SD. We compared fixed and random effects models using the deviance information criterion (DIC), a measure of model fit that penalises model complexity. The model with lower values on the DIC was preferred, with differences of three or more units considered meaningful. ${ }^{14}$ If two models had a similar DIC, a fixed-effects model was preferred unless there was heterogeneity in the pairwise comparison, in which case a random-effects model was used. Inconsistency was assessed by comparing the model fit and between-study heterogeneity from the NMA models with those from an unrelated effects (inconsistency) model. ${ }^{15}$

The presence of heterogeneity was assessed by comparing a between-trials SD to the size of the relative treatment effects, on $\log$-scale for OR and HR. If the between-trials SD approximates the size of treatment effect, heterogeneity is likely very high so that results from a future trial could include zero or even harmful effects. Heterogeneity was further explored by fitting covariates (ie, $\mathrm{FEV}_{1}$ at baseline, treatment duration (a minimum of 6 months), publication status (published vs unpublished) and smoking status) in a meta-regression analysis. ${ }^{16}$ A subgroup interaction model was used for the treatment duration and a continuous covariate model was used for the rest of the covariates. 
We conducted traditional pairwise meta-analyses, considering only direct evidence comparing the combination therapy with monotherapies or placebo using the same outcome variables. For the pairwise meta-analysis, we tested heterogeneity between trials with $\mathrm{I}^{2}$ statistic with $\mathrm{I}^{2}>50 \%$ indicating significant heterogeneity. A random effects model (DerSimonian-Laird) was used if significant heterogeneity was detected. A fixed-effects model was used otherwise. Haldane correction was applied by adding 0.5 to each count when a data set contained zero in any cell to make a calculation possible for the main effect or variance. ${ }^{17}$ Results from our NMA were qualitatively compared with direct pairwise estimates. The data analysis was performed using meta-analysis software (StatsDirect V.2.7.8, StatsDirect, Cheshire UK).

Sample size calculations and power analyses were conducted for clinically relevant outcomes such as SGRQ and TDI responders and COPD exacerbations with a method described by Thorlund and Mills. ${ }^{18}$ A required sample size was calculated by applying a mean event rate of the comparator arm from the included trials, a type I error of $5 \%$ and a power of $90 \%$, expecting to detect an additional $20 \%$ relative efficacy with the combination arm. Heterogeneity was estimated from $\mathrm{I}^{2}$ index of a head-to-head comparison and used for correcting the sample sizes.

\section{RESULTS}

\section{Study selection}

The electronic database searches identified 112 citations. Ninety-seven studies were excluded on abstract review. The remaining 15 studies were reviewed for further details. Additional five studies were excluded for various reasons as shown in figure 1 . Further search on manufactures' website and internet identified 10 additional studies including 3 unpublished studies. We included 23 trials from 20 reports with a total of 27172 randomised patients. ${ }^{19-38}$ The study and patient characteristics are presented in table 1.

Formoterol, indacaterol, olodaterol, salmeterol and vilanterol were grouped as LABA and aclidinium, glycopyrronium, umeclidinium and tiotropium were grouped as LAMA. The mean age ranged from 61.3 years to 69.3 years. The proportion of male

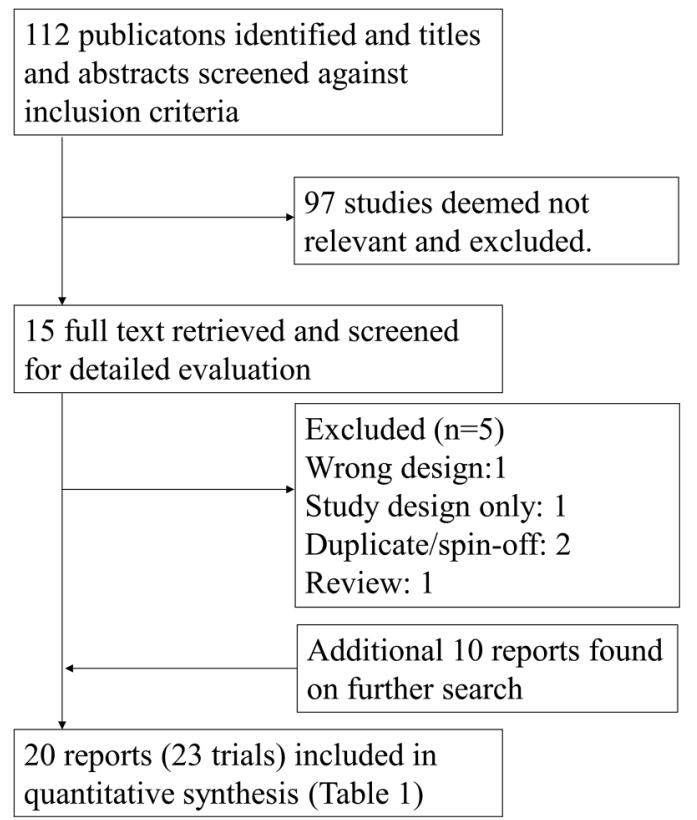

Figure 1 Flow of study selection. patients and current smokers ranged from 52\% to $96 \%$ and $26 \%$ to $63 \%$, respectively. The mean baseline $\mathrm{FEV}_{1}$ ranged from $0.90 \mathrm{~L}$ to $1.5 \mathrm{~L}$. $\mathrm{FEV}_{1}$ per cent predicted ranged from $37.2 \%$ to $57.4 \%$. The network of treatments is displayed in figure 2. The treatments formed a closed network, which was amenable to a NMA.

\section{Methodological quality of included studies}

Generally, the risk of bias in the included studies was deemed moderate to low. Allocation concealment was appropriate in 16 studies, and unclear in 3 studies. All trials presented intention-to-treat analyses except for two trials which excluded 2 patients out of 1134 and 1137 patients who did not receive the study treatment. ${ }^{26}$ Nineteen studies were double blinded (see online supplementary table S3). In the opinion of the authors, there were no studies that clearly should have been excluded from the analysis because of differences in baseline characteristics or poor quality.

\section{Consistency assessment (similarity of participants, interventions and trial methodology)}

All trials were consistent in their key inclusion and exclusion criteria (see online supplementary table S4). All studies recruited patients aged $>35-40$ years with a diagnosis of COPD in accordance with the American Thoracic Society-European Respiratory Society or GOLD guidelines, at least 10 pack-years of smoking history, and moderate or severe disease with $\mathrm{FEV}_{1}$ ranging 30$70 \%$ of predicted. Patients with asthma and other respiratory or cardiovascular disease were excluded in all trials. The concomitant use of a fixed dose of inhaled corticosteroids (ICS) was allowed in most studies, prohibited in two studies ${ }^{26} 38$ and unclear in one study $^{35}$ which was addressed in a sensitivity analysis. A recent COPD exacerbation within a month of study entry was usually excluded from the study. Baseline characteristics of studied patients were similar in all included studies (table 1 ) as well as in class pairwise comparisons (eg, LABA vs combination, LAMA vs Placebo, see online supplementary table S5). Baseline $\mathrm{FEV}_{1}$ was somehow lower in the combination versus LAMA comparison, but summary baseline characteristics were comparable across pairwise comparisons between classes. Trial duration varied across studies, which was addressed by including only data relevant to the time points specified or by modelling the data as hazards with the binomialcomplementary log-log (cloglog) model which allows for the different follow-up time. In general, characteristics of participants, interventions and trial methodology were fairly comparable in all studies and across pairwise comparisons, and therefore we found nothing to suggest that the consistency assumption may not hold.

\section{Network meta-analysis}

The clinical trials were synthesised with a NMA. The individual study results are presented in online supplementary table S6-S8. The autocorrelation plots showed that throughout the iterative process the autocorrelation was satisfactorily reduced to a nominal amount and the Brooks-Gelman-Rubin plots showed that the model had converged satisfactorily. ${ }^{39}$ When examining outcome measures, a fixed-effects model showed largely similar DIC values and results as a random-effects model. A random-effects model was chosen in all outcomes according to our prespecified selection criteria except for CFB in SGRQ at 3 months, TDI, proportion of TDI responders, severe exacerbations, mortality and total SAEs. The between-study heterogeneity and DICs were similar between the NMA and inconsistency models suggesting no evidence of inconsistency in the network, although this should be interpreted with caution as there may 
Table 1 Study characteristics of included trials

\begin{tabular}{|c|c|c|c|c|c|c|c|c|}
\hline Study, year & $\begin{array}{l}\text { No. of } \\
\text { patients* }\end{array}$ & $\begin{array}{l}\text { Duration of } \\
\text { treatment (weeks) }\end{array}$ & $\begin{array}{l}\text { Treatment comparisons } \\
(\mu \mathrm{g})\end{array}$ & Mean age & Male \% & $\begin{array}{l}\text { Current } \\
\text { smoker } \%\end{array}$ & $\begin{array}{l}\text { Baseline } \\
\text { FEV } \% \text { t }\end{array}$ & $\begin{array}{l}\text { Baseline } \\
\text { FEV }_{1}(\mathrm{~L}) \ddagger\end{array}$ \\
\hline Buhl et al $2015^{19}$ & 5162 & 52 & $\begin{array}{l}\text { TIO/OLO 5/5 } \\
\text { TIO/OLO 2.5/5 } \\
\text { TIO } 5 \\
\text { TIO } 2.5 \\
\text { OLO } 5\end{array}$ & 64.0 & 73 & 37 & 50.0 & 1.17 \\
\hline Celli et al $2014^{20}$ & 1489 & 24 & $\begin{array}{l}\text { UMEC/VI 125/25 } \\
\text { UMEC } 125 \\
\text { VI } 25 \\
\text { Placebo }\end{array}$ & 62.9 & 65 & 52 & 48.2 & 1.28 \\
\hline Decramer et al $2014^{21}$ & 843 & 24 & $\begin{array}{l}\text { UMEC/VI 125/25 } \\
\text { UMEC/NI 62.5/25 } \\
\text { VI } 25 \\
\text { TIO } 18\end{array}$ & 62.9 & 69 & 51 & 47.7 & 1.31 \\
\hline Decramer et al $2014^{21}$ & 869 & 24 & $\begin{array}{l}\text { UMEC/NI 125/25 } \\
\text { UMEC/NI 62.5/25 } \\
\text { UMEC } 125 \\
\text { TIO } 18\end{array}$ & 64.6 & 68 & 45 & 47.1 & 1.16 \\
\hline$D^{\prime}$ Urzo et al $2014^{22}$ & 1669 & 24 & $\begin{array}{l}\text { ACL/FM 400/12 } \\
\text { ACL/FM 400/6 } \\
\text { ACL } 400 \\
\text { FM } 12 \\
\text { Placebo }\end{array}$ & 63.9 & 53 & 52 & 53.5 & 1.36 \\
\hline Donohue et al $2014^{31}$ & 562 & 52 & $\begin{array}{l}\text { UMEC/VI 125/25 } \\
\text { UMEC } 125 \\
\text { Placebo }\end{array}$ & 61.3 & 67 & 63 & 54.7 & 1.49 \\
\hline Maleki-Yazdi et al $2014^{23}$ & 905 & 24 & $\begin{array}{l}\text { UMEC/NI 62.5/25 } \\
\text { TIO } 18\end{array}$ & 62.3 & 68 & 57 & 46.3 & $1.41^{\S}$ \\
\hline Singh et al $2014^{24}$ & 1729 & 24 & $\begin{array}{l}\text { ACL/FM 400/12 } \\
\text { ACL/FM 400/6 } \\
\text { ACL } 400 \\
\text { FM } 12 \\
\text { Placebo }\end{array}$ & 63.2 & 68 & 47 & 54.3 & 1.41 \\
\hline Vincken et al $2014^{25}$ & 447 & 12 & $\begin{array}{l}\text { IND/Glyco 110/50 } \\
\text { IND } 150\end{array}$ & 63.6 & 81 & 42 & 54.9 & 1.46 \\
\hline $\begin{array}{l}\text { ZuWallack et al } 2014^{26} \S \\
\text { (ANHELTO } 1 \text { and } 2 \text { ) }\end{array}$ & 2267 & 12 & $\begin{array}{l}\text { TIO/OLO 18/5 } \\
\text { TIO } 18\end{array}$ & 64.3 & 52 & 49 & 53.7 & 1.25 \\
\hline Bateman et al $2013^{27}$ & 2135 & 26 & $\begin{array}{l}\text { IND/Glyco } 110 / 50 \\
\text { IND } 150 \\
\text { Glyco } 50 \\
\text { TIO } 18 \\
\text { Placebo }\end{array}$ & 63.9 & 75 & 40 & 55.2 & 1.30 \\
\hline Dahl et al $2013^{28}$ & 338 & 52 & $\begin{array}{l}\text { IND/Glyco 110/50 } \\
\text { Placebo }\end{array}$ & 62.6 & 77 & 45 & 57.4 & 1.45 \\
\hline Donohue et al $2013^{29}$ & 1532 & 24 & $\begin{array}{l}\text { UMEC/VI } 62.5 / 25 \\
\text { UMEC } 62.5 \\
\text { VI } 25 \\
\text { Placebo }\end{array}$ & 63.1 & 71 & 50 & 47.4 & 1.23 \\
\hline Wedzicha et al $2013^{30}$ & 2205 & 64 & $\begin{array}{l}\text { IND/Glyco } 110 / 50 \\
\text { Glyco } 50 \\
\text { TIO } 18\end{array}$ & 63.3 & 75 & 38 & 37.2 & 0.90 \\
\hline DB2114417 $2012^{32}$ & 641 & 12 & $\begin{array}{l}\text { UMEC/VI 125/25 } \\
\text { UMEC/NI 62.5/25 } \\
\text { VI } 25 \\
\text { UMEC } 125 \\
\text { UMEC } 62.5 \\
\text { Placebo }\end{array}$ & 61.6 & 56 & 63 & NR & 1.44 \\
\hline DB2114418 $2012^{33}$ & 554 & 12 & $\begin{array}{l}\text { UMEC/NI 125/25 } \\
\text { UMEC/NI 62.5/25 } \\
\text { VI } 25 \\
\text { UMEC } 125 \\
\text { UMEC } 62.5 \\
\text { Placebo }\end{array}$ & 62.6 & 55 & 61 & NR & 1.32 \\
\hline Mahler et al $2012^{34}$ & 1131 & 12 & $\begin{array}{l}\text { TIO } 18 \text { /IND } 150 \\
\text { TIO } 18\end{array}$ & 63.7 & 69 & 38 & 48.6 & 1.15 \\
\hline Mahler et al $2012^{34}$ & 1142 & 12 & $\begin{array}{l}\text { TIO } 18 \text { /IND } 150 \\
\text { TIO } 18\end{array}$ & 63 & 66 & 40 & 48.6 & 1.14 \\
\hline
\end{tabular}


Table 1 Continued

\begin{tabular}{|c|c|c|c|c|c|c|c|c|}
\hline Study, year & $\begin{array}{l}\text { No. of } \\
\text { patients* }\end{array}$ & $\begin{array}{l}\text { Duration of } \\
\text { treatment (weeks) }\end{array}$ & $\begin{array}{l}\text { Treatment comparisons } \\
(\mu \mathrm{g})\end{array}$ & Mean age & Male \% & $\begin{array}{l}\text { Current } \\
\text { smoker } \%\end{array}$ & $\begin{array}{l}\text { Baseline } \\
\text { FEV }_{1} \% t\end{array}$ & $\begin{array}{l}\text { Baseline } \\
\text { FEV }_{1} \text { (L) } ¥\end{array}$ \\
\hline Novartis A1301 $2012^{35}$ & 158 & 52 & $\begin{array}{l}\text { IND/Glyco 110/50 } \\
\text { TIO } 18\end{array}$ & 69.3 & 96 & NR & NR & 1.339 \\
\hline Tashkin et al $2009^{36}$ & 243 & 12 & $\begin{array}{l}\text { TIO } 18 \text { /FM } 12 \\
\text { TIO } 18\end{array}$ & 63.9 & 66 & 47 & NR & NR \\
\hline Vogelmeier et al $2008^{37}$ & 847 & 24 & $\begin{array}{l}\text { TIO } 18 \text { /FM } 10 \\
\text { FM } 10 \\
\text { TIO } 18 \\
\text { Placebo }\end{array}$ & 62.6 & 78 & NR & 51 & 1.5 \\
\hline Aaron et al $2007^{38}$ & 304 & 52 & $\begin{array}{l}\text { TIO 18/SAL } 50 \\
\text { TIO } 18\end{array}$ & 67.9 & 56 & 26 & 41.7 & 1.01 \\
\hline
\end{tabular}

${ }^{*}$ Number of patients included in this analysis.

tPostbronchodilator.

‡Prebronchodilator.

§Includes 2 trials making a total of 23 trials.

IAt week 3.

ACL, aclidinium; FM, formoterol; Glyco, glycopyrronium; IND, indacaterol; NR, not reported; OLO, olodaterol; SAL, salmeterol; TIO, tiotropium; UMEC, umeclidinium; VI, vilanterol.

not be sufficient power to detect inconsistency. Ranking results of each outcome are presented in table 2.

\section{$\mathrm{FEV}_{1}$}

Trough $\mathrm{FEV}_{1}$ data were available in 13 trials, 12 trials and 4 trials at 3 months, 6 months and 12 months $(n=12224,16065$ and 4836, respectively). Improvement in trough $\mathrm{FEV}_{1}$ to the end of the trials was greater with LABA/LAMA combinations than with placebo, LABAs or LAMAs at all time points. LABA/LAMA combinations were ranked first $(95 \% \mathrm{CrI} 1,1)$ at all time points, with a mean improvement over placebo of $201 \mathrm{~mL}$ (95\% CrI 172, 230) to $243 \mathrm{ml}(95 \% \mathrm{CrI} 139,351)$. LAMAs and LABAs were ranked second and third with the MDs of $64 \mathrm{~mL}(95 \% \mathrm{CrI} 51,78)$ to $73 \mathrm{~mL}(95 \% \mathrm{CrI} \mathrm{43,149)}$ and $95 \mathrm{~mL}(95 \% \mathrm{CrI} 71,117)$ to $104 \mathrm{~mL}$ (95\% CrI 84, 126) compared with LABA/LAMA combinations. Class differences did not appear significantly different at 3 months, 6 months and 12 months, except for LABAs at 12 months at which time point data were not available (figure 3). Wider $95 \%$ CrIs were observed at 12 months as the number of included studies decreased.

\section{Health-related quality of life and symptom scales (SGRQ} and TDI scores and responders)

The data for CFB in SGRQ and TDI were available in nine and six trials at 3 months and nine and eight trials at 6 months

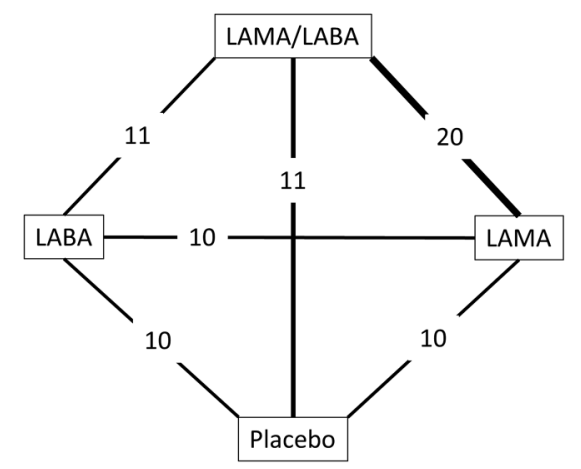

Figure 2 Diagram displaying the network of four arms involved in the Bayesian analysis. The links between nodes are used to indicate a direct comparison between pairs of treatments. The numbers shown along the link lines indicate the number of trials comparing pairs of treatments head-to-head. LABA, long-acting $\beta$-agonist; LAMA, long-acting muscarinic antagonist.
( $\mathrm{n}=12$ 042, 7315, 12716 and 14568 , respectively). The data for SGRQ and TDI responders at 6 months were available in 12 and 7 trials ( $\mathrm{n}=18536$ and 9045, respectively). The combination therapy was ranked highest, followed by LABAs and LAMAs in all SGRQ outcomes. The efficacy of combination therapy in CFB in SGRQ was less prominent at 6 months as compared with 3 months, especially with LABAs (MD -4.6 (95\% CrI -5.9, -3.3), -2.3 (95\% CrI -3.3, -1.3) and -2.3 (95\% CrI $-2.9,-1.7)$ for placebo, LABAs and LAMAs, respectively at 3 months and -4.1 (95\% CrI $-5.9,-2.3),-1.1$ (95\% CrI $-2.5,0.4)$ and $-1.6(95 \%$ CrI $-2.8,-0.5)$ at 6 months, figure 4A). Although the MD and its $95 \%$ CrI between combination therapy and monotherapies did not reach the minimum clinically important difference of 4 points in SGRQ score, LAMA/LABA combinations were associated with a significantly greater proportion of SGRQ responders compared with LAMAs and LABAs (OR 1.23 (95\% CrI 1.06, 1.39) and1.24 (95\% CrI $1.11,1.36)$, respectively, figure 5).

As for TDI, the combination therapy was ranked highest, followed by LABAs or LAMAs. The combination therapy yielded a significant improvement in TDI score compared with placebo, LABAs and LAMAs at 3 months (MD 1.21 (95\% CrI 0.95, 1.48), 0.37 (95\% CrI 0.16, 0.57) and 0.41 (95\% CrI 0.23, 0.59), respectively). The class differences remained constant and statistically significant at 6 months (figure 4B). Although the MD and its $95 \% \mathrm{CrI}$ between combination therapy and monotherapies did not reach the minimum clinically important difference of 1 point in TDI, LAMA/LABA combinations were associated with a significantly greater proportion of TDI responders compared with LAMAs and LABAs (OR 1.34 (95\% CrI 1.16, 1.56) and 1.30 (95\% CrI 1.13, 1.48), respectively, figure 5). The 95\% CrIs of ranking suggested that only combination therapy could be ranked first in all SGRQ and TDI outcomes (table 2).

\section{COPD exacerbations}

COPD exacerbation data were available in 16 trials $(n=18224)$ for moderate-to-severe exacerbations and in 19 trials $(n=25401)$ for severe exacerbations. LABA/LAMA combinations were ranked first and second for the prevention of moderate-to-severe and severe exacerbations with a probability of being the best therapy of $97.0 \%$ and $30.2 \%$, respectively. The combination therapy was associated with significantly fewer moderate-to-severe exacerbations compared with placebo and LABAs (HR 0.66(95\% CrI 0.57, 0.77), 0.82 (95\% CrI 0.73, 
Table 2 Probability of best therapy, SUCRA values and ranking of therapy

\begin{tabular}{|c|c|c|c|c|c|c|c|}
\hline & & & & & & & \\
\hline & & & \multirow{3}{*}{$\begin{array}{l}\text { Median ranking } \\
(95 \% \mathrm{Crl})\end{array}$} & & \multirow{2}{*}{$\begin{array}{l}\text { Probability of being the best } \\
\text { therapy }(\%)\end{array}$} & \multirow{2}{*}{$\begin{array}{l}\text { SUCRA } \\
\text { value }(\%)\end{array}$} & \multirow{2}{*}{$\begin{array}{l}\text { Median ranking } \\
(95 \% \mathrm{Crl})\end{array}$} \\
\hline & \multirow{2}{*}{$\begin{array}{l}\text { Probability of being the best } \\
\text { therapy }(\%)\end{array}$} & \multirow{2}{*}{$\begin{array}{l}\text { SUCRA } \\
\text { value }(\%)\end{array}$} & & \multirow{3}{*}{$\begin{array}{l}\text { LAMA } \\
\text { LAMA/LABA }\end{array}$} & & & \\
\hline & & & & & 0.6 & 14.5 & $4(2-4)$ \\
\hline Treatment & CFB in FEV $1(\mathrm{~L})-3$ months & & & & 7.1 & 52.7 & $3(1-4)$ \\
\hline Placebo & 0 & 0 & $4(4-4)$ & & \multicolumn{2}{|l|}{ Total serious adverse events } & \\
\hline LABA & 0 & 33.4 & $3(3-3)$ & Placebo & 62.7 & 76.4 & $1(1-4)$ \\
\hline LAMA & 0 & 66.6 & $2(2-2)$ & LABA & 6.6 & 23.6 & $4(1-4)$ \\
\hline LABA/LAMA & 100 & 100 & $1(1-1)$ & LAMA & 26.0 & 64.7 & $2(1-4)$ \\
\hline Treatment & CFB in $\mathrm{FEV}_{1}(\mathrm{~L})-6$ months & & & LAMA/LABA & 4.7 & 35.2 & $3(1-4)$ \\
\hline Placebo & 0 & 0 & $4(4-4)$ & & \multicolumn{2}{|l|}{ Cardiac serious adverse events } & \\
\hline LABA & 0 & 33.6 & $3(3-3)$ & Placebo & 89.6 & 94.7 & $1(1-3)$ \\
\hline LAMA & 0 & 66.4 & $2(2-2)$ & LABA & 2.1 & 22.3 & $4(2-4)$ \\
\hline \multirow[t]{2}{*}{ LABA/LAMA } & 100 & 100 & $1(1-1)$ & LAMA & 1.6 & 28.3 & $3(2-4)$ \\
\hline & \multicolumn{2}{|l|}{ CFB in $\mathrm{FEV}_{1}(\mathrm{~L})-12$ months } & & LAMA/LABA & 6.7 & 54.6 & $2(1-4)$ \\
\hline Placebo & 0.1 & 0.5 & $3(3-3)$ & & \multicolumn{2}{|l|}{ Dropout due to adverse event } & \\
\hline LABA & N/A & $\mathrm{N} / \mathrm{A}$ & N/A & Placebo & 22.7 & 42.8 & $3(1-4)$ \\
\hline LAMA & 2.1 & 50.7 & $2(2-2)$ & LABA & 11.7 & 29.6 & $3(1-4)$ \\
\hline \multirow[t]{2}{*}{ LABA/LAMA } & 97.7 & 98.8 & $1(1-1)$ & LAMA & 42.0 & 70.0 & $2(1-4)$ \\
\hline & \multicolumn{2}{|l|}{ CFB in SGRQ -3 months } & & LAMA/LABA & 23.5 & 57.6 & $2(1-4)$ \\
\hline Placebo & 0 & 0 & $4(4-4)$ & \multirow{5}{*}{\multicolumn{4}{|c|}{$\begin{array}{l}\text { *Defined as a subject with a SGRQ score of } 4 \text { units below baseline or lower. } \\
\text { tDefined as a subject with a TDI score of } 1 \text { unit or more. } \\
\text { CFB, change from baseline; Crl, credible interval; LABA, long-acting } \beta \text {-agonist; LAMA, } \\
\text { long-acting muscarinic antagonist; N/A, not applicable; SGRQ, St. George's } \\
\text { Respiratory Questionnaire; SUCRA, surface under the cumulative ranking curve; TDI, } \\
\text { Transitional Dyspnoea Index. }\end{array}$}} \\
\hline LABA & 0 & 49.0 & $2(2-3)$ & & & & \\
\hline LAMA & 0 & 51.0 & $3(2-3)$ & & & & \\
\hline \multirow[t]{2}{*}{ LAMA/LABA } & 100 & 100 & $1(1-1)$ & & & & \\
\hline & \multicolumn{2}{|l|}{ CFB in SGRQ -6 months } & & & & & \\
\hline
\end{tabular}

\begin{tabular}{|c|c|c|c|}
\hline Placebo & 0 & 0.1 & $4(4-4)$ \\
\hline LABA & 0.6 & 52.2 & $2(2-3)$ \\
\hline LAMA & 0.1 & 47.9 & $3(2-3)$ \\
\hline \multirow{2}{*}{ LAMA/LABA } & 99.2 & 99.7 & $1(1-2)$ \\
\hline & SGRQ responder* -6 months & & \\
\hline Placebo & 0 & 0.4 & $4(4-4)$ \\
\hline LABA & 0.4 & 67.2 & $2(2-3)$ \\
\hline LAMA & 0 & 36.8 & $3(2-3)$ \\
\hline \multirow[t]{2}{*}{ LAMA/LABA } & 99.5 & 95.6 & $1(1-2)$ \\
\hline & TDI-3 months & & \\
\hline Placebo & 0 & 0 & $4(4-4)$ \\
\hline LABA & 0 & 55.7 & $2(2-3)$ \\
\hline LAMA & 0 & 44.3 & $3(2-3)$ \\
\hline \multirow[t]{2}{*}{ LABA/LAMA } & 99.9 & 100 & $1(1-1)$ \\
\hline & TDI-6 months & & \\
\hline Placebo & 0 & 0 & $4(4-4)$ \\
\hline LABA & 0 & 43.0 & $3(2-3)$ \\
\hline LAMA & 0 & 57.0 & $2(2-3)$ \\
\hline \multirow[t]{2}{*}{ LABA/LAMA } & 99.4 & 100 & $1(1-1)$ \\
\hline & TDI respondert- 6 months & & \\
\hline Placebo & 0 & 0 & $4(4-4)$ \\
\hline LABA & 0 & 44.2 & $3(2-3)$ \\
\hline LAMA & 0.1 & 55.8 & $2(2-3)$ \\
\hline \multirow[t]{2}{*}{ LABA/LAMA } & 99.9 & 100 & $1(1-1)$ \\
\hline & Moderate-to-severe exacerbations & & \\
\hline Placebo & 0 & 2.6 & $4(4-4)$ \\
\hline LABA & 0.2 & 34.3 & $3(2-3)$ \\
\hline LAMA & 2.9 & 66.5 & $2(1-3)$ \\
\hline \multirow[t]{2}{*}{ LAMA/LABA } & 97.0 & 99.0 & $1(1-2)$ \\
\hline & Severe exacerbations & & \\
\hline Placebo & 4.6 & 10.2 & $4(1-4)$ \\
\hline LABA & 37.4 & 66.0 & $2(1-4)$ \\
\hline LAMA & 7.5 & 44.8 & $3(1-4)$ \\
\hline \multirow[t]{2}{*}{ LAMA/LABA } & 50.5 & 79.0 & $1(1-3)$ \\
\hline & Mortality & & \\
\hline Placebo & 84.8 & 91.4 & $1(1-4)$ \\
\hline LABA & 7.6 & 41.3 & $3(1-4)$ \\
\hline
\end{tabular}

Table 2 Continued

0.93), respectively), but not when compared with LAMAs (HR 0.92 (95\% CrI 0.84, 1.00)). LAMAs had a median rank of 2 in preventing moderate-to-severe exacerbations and the 95\% CrI suggested that they could also be ranked first, second or third (median ranking 2 (95\% CrI 1, 3)). There were no significant differences in severe exacerbations associated with LABA/LAMA combinations compared with placebo, LABAs or LAMAs and there was a large degree of overlap in ranking (figure 6 and table 2).

\section{Adverse events}

The results of safety outcomes are presented in table 3 . There were no significant differences in mortality, total SAEs or dropouts due to adverse event among all comparators (table 3). arm including placebo could be ranked as the best therapy in all safety outcomes except for LAMAs in mortality and cardiac SAEs and LABAs in cardiac SAEs. Placebo was ranked highest in mortality, total SAEs and cardiac SAEs. LABA/LAMA combinations were ranked second in mortality, cardiac SAEs and dropouts due to adverse event, but again, there was a large degree of overlap (table 3).

\section{Assessment of consistency and exploration of heterogeneity}

The between-trials SDs were relatively large compared with the relative treatment effects in severe exacerbations, mortality, total SAEs, cardiac SAEs and dropouts due to adverse event (see online supplementary table S9). The meta-regression adjustment for the proportion of active smokers, $\mathrm{FEV}_{1}$ at baseline, study duration (a minimum of 6 months), and publication status (published vs unpublished) did not alter the main findings. Between-trials heterogeneity was either unchanged, increased or only slightly reduced with the introduction of those covariates. Comparisons between network and direct pairwise meta-analyses were similar in magnitude and direction of effect
There was considerable overlap in CrIs and rankings. Any 


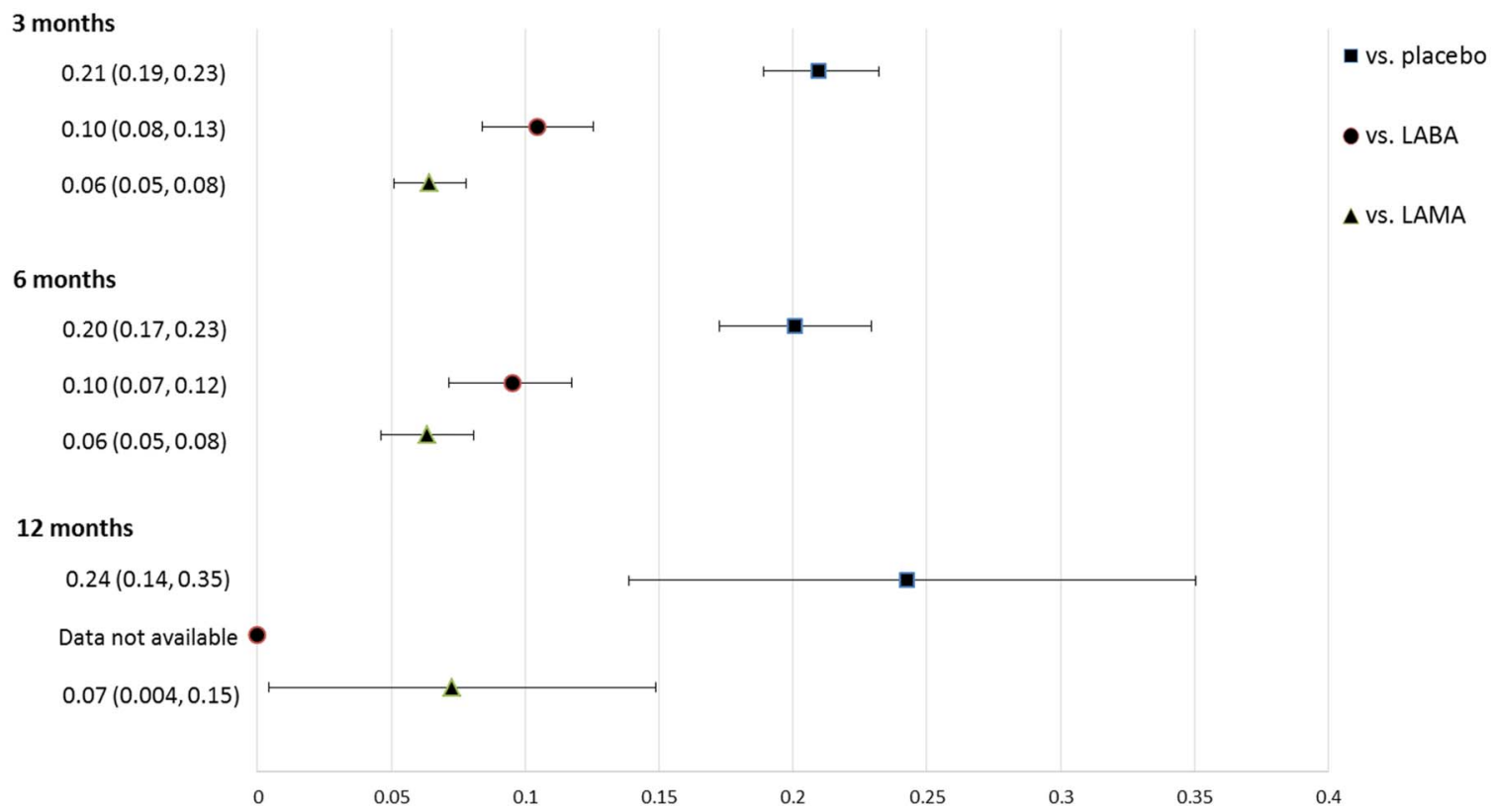

Figure 3 Summary effects of LABA/LAMA combination versus comparators on changes in trough FEV 1 at 3 months, 6 months and 12 months. Note: Mean difference in litres (95\% credible interval). LABA, long-acting $\beta$-agonist; LAMA, long-acting muscarinic antagonist.

estimates, with the exception of the combination versus LAMA comparison in moderate-to-severe exacerbations and the combination versus LAMA comparison in dropouts due to adverse event. However, these inconsistencies did not alter the main findings (see online supplementary table S10). Two studies included a randomly assigned group that received tiotropium as an open-label treatment. ${ }^{30} 37$ The concomitant use of ICS was prohibited in two studies ${ }^{26} 38$ and unclear in one study. ${ }^{30}$ We performed a sensitivity analysis excluding these studies and the results were essentially unchanged.

\section{Power analyses and sample size calculations}

The heterogeneity-corrected effective total sample size for the SGRQ and TDI responders and moderate-to-severe exacerbations was greater than the required sample size to detect additional $20 \%$ relative efficacy with a power of $90 \%$ (see online supplementary table S11). Statistical power for combination therapy versus comparators was $95 \%$ or greater in those outcomes. On the other hand, the effective total sample size for severe exacerbations was substantially smaller than the required sample size except for the combination therapy versus LAMA comparison. Statistical power estimates for the combination therapy versus placebo, LABA and LAMA comparisons were $29.8 \%, 55.5 \%$ and $93.5 \%$, respectively, in severe exacerbations.

\section{DISCUSSION}

Our systematic review of the currently available randomised trials of LABA/LAMA combinations for stable COPD demonstrated that LABA/LAMA combinations yielded a greater improvement in trough $\mathrm{FEV}_{1}$, and SGRQ and TDI scores than monotherapies. The ranking statistics demonstrated that combination therapy was the most effective strategy in improving lung function, quality of life and symptom scores as well as in reducing moderate-to-severe exacerbations. The combination therapy was associated with a significantly greater proportion of SGRQ and TDI responders than monotherapies. The combination therapy was ranked highest in reducing moderate-to-severe exacerbations and was associated with significantly fewer exacerbations than LABAs, but not when compared with LAMAs. LAMAs could also be ranked first in reducing moderate-to-severe exacerbations. There were no statistically significant differences among all comparators in severe exacerbations or safety outcomes, including mortality, total SAEs, cardiac SAEs and dropouts due to adverse event. The sample size analysis suggested that the analyses for severe exacerbations were underpowered except for the combination versus LAMA comparison. The sample size for SGRQ and TDI responders and moderate-to-severe exacerbations appeared adequate.

The results of our analysis are in line with a previous meta-analysis which demonstrated tiotropium/LABA combinations were associated with a small increase in lung function and a statistically significant improvement in quality of life compared with tiotropium alone. Improvement in other secondary outcomes, such as COPD exacerbations and SAEs was similar between both groups. ${ }^{40}$ It is not surprising that dual therapies were not associated with significantly fewer exacerbations compared with LAMAs in the current analysis given that the concomitant use of LABA did not enhance the efficacy of LAMAs in reducing COPD exacerbations in a recent meta-regression analysis. ${ }^{41} \mathrm{~A}$ similar phenomenon was observed among shortacting bronchodilators. Only ipratropium containing arms had reduced COPD exacerbations and adding albuterol to ipratropium did not reduce COPD exacerbations compared with ipratropium alone. ${ }^{42}$ It was speculated that alterations in mucus production, rheology by glands, or mucus clearance in small airways were primarily responsible for COPD exacerbations which were favourably affected by anticholinergics rather than by $\beta 2$ agonists. The above notion is further supported by the current analysis with the strength of the NMA, which is the correct inclusion of multiarm trials, of which this network had many, including several studies comparing all four interventions.

It is important to note the limitations of our study. First, heterogeneity was observed in pairwise and network meta-analyses. None of the trial-level covariates we assessed explained the heterogeneity. Patient and study characteristics of the included 


\section{A Changes from baseline in St. George's Respiratory Questionnaire}

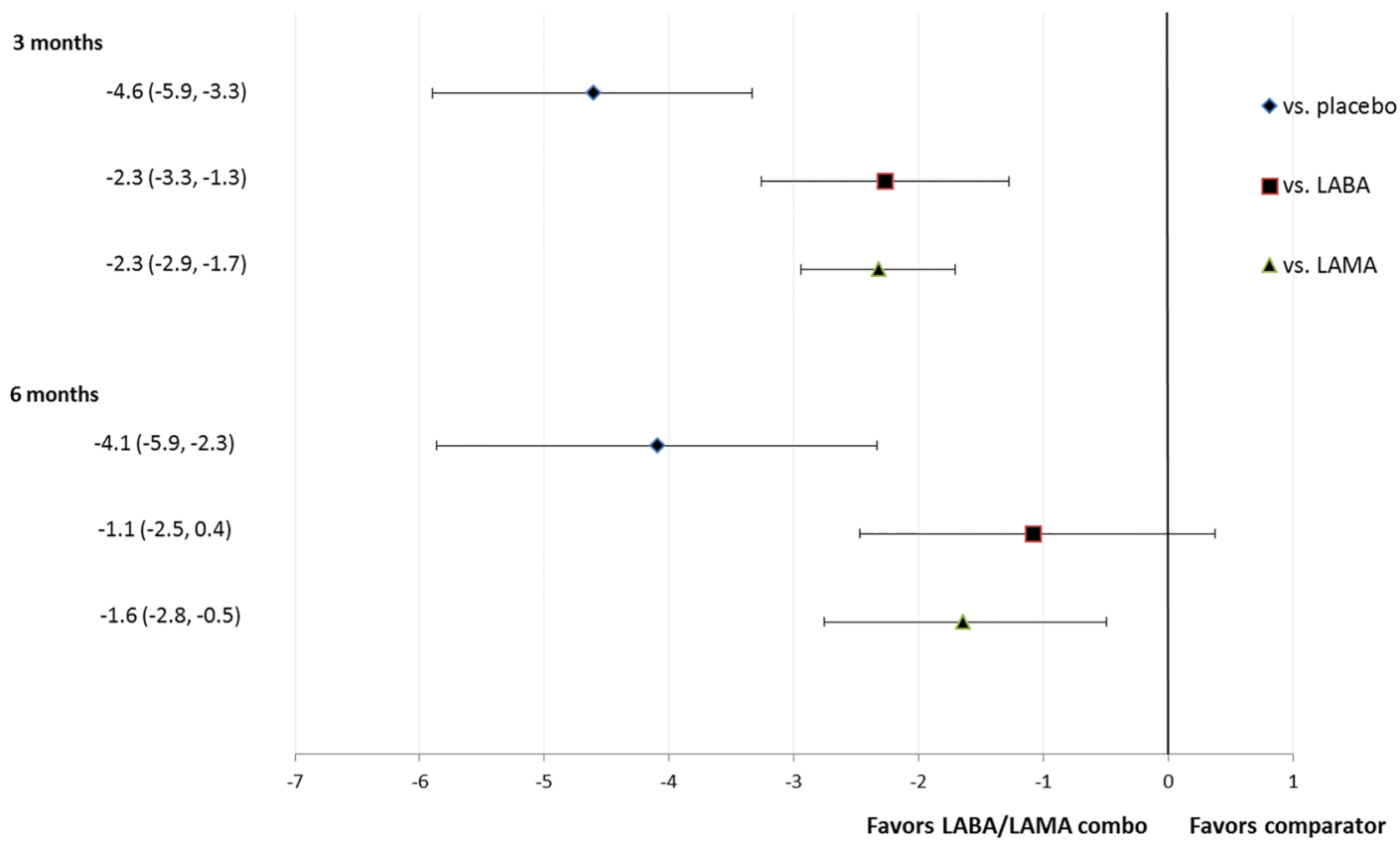

\section{B Transition Dyspnea Index}

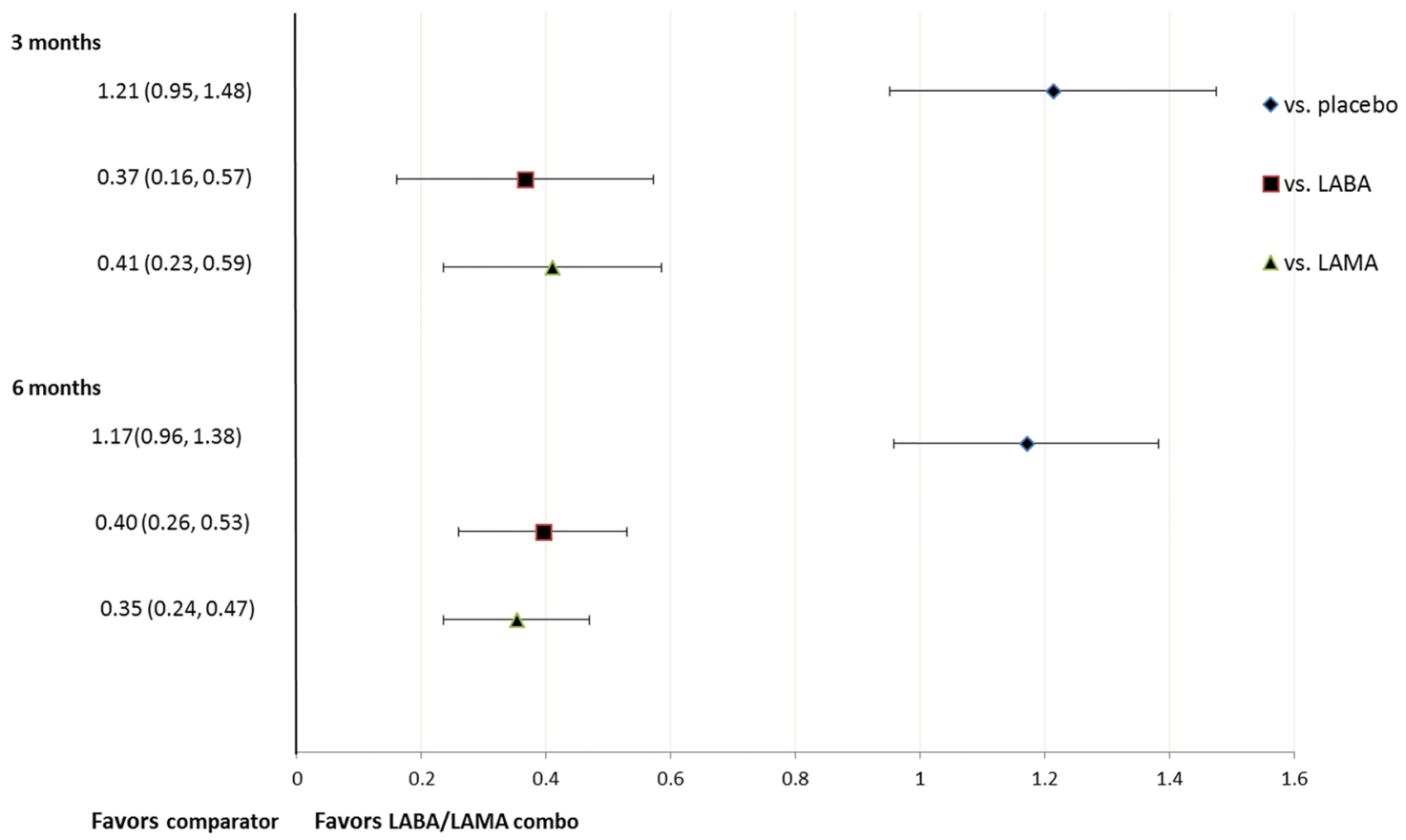

Figure 4 Summary effects of LABA/LAMA combination versus comparators on changes in (A) St. George's Respiratory Questionnaire and (B) Transition Dyspnoea Index at 3 months and 6 months. Note: Mean difference (95\% credible interval). LABA, long-acting $\beta$-agonist; LAMA, long-acting muscarinic antagonist.

studies were relatively homogenous, but between-trial comparisons are known to be vulnerable to ecological bias. ${ }^{13}$ The subgroup analysis to assess biases by systematic differences between studies was also compromised due to limited information. For example, the proportion of current smokers and baseline prebronchodilator $\mathrm{FEV}_{1}$ values were not available in a few studies included in this analysis (table 1). Individual patient data would be necessary to avoid ecological bias and gain a much greater statistical power to detect a true covariate effect. Other effect modifiers including body mass index, Medical Research Council dyspnoea score, exercise capacity (6-min walk distance), presence of emphysema on chest CT and cardiac comorbidities may 


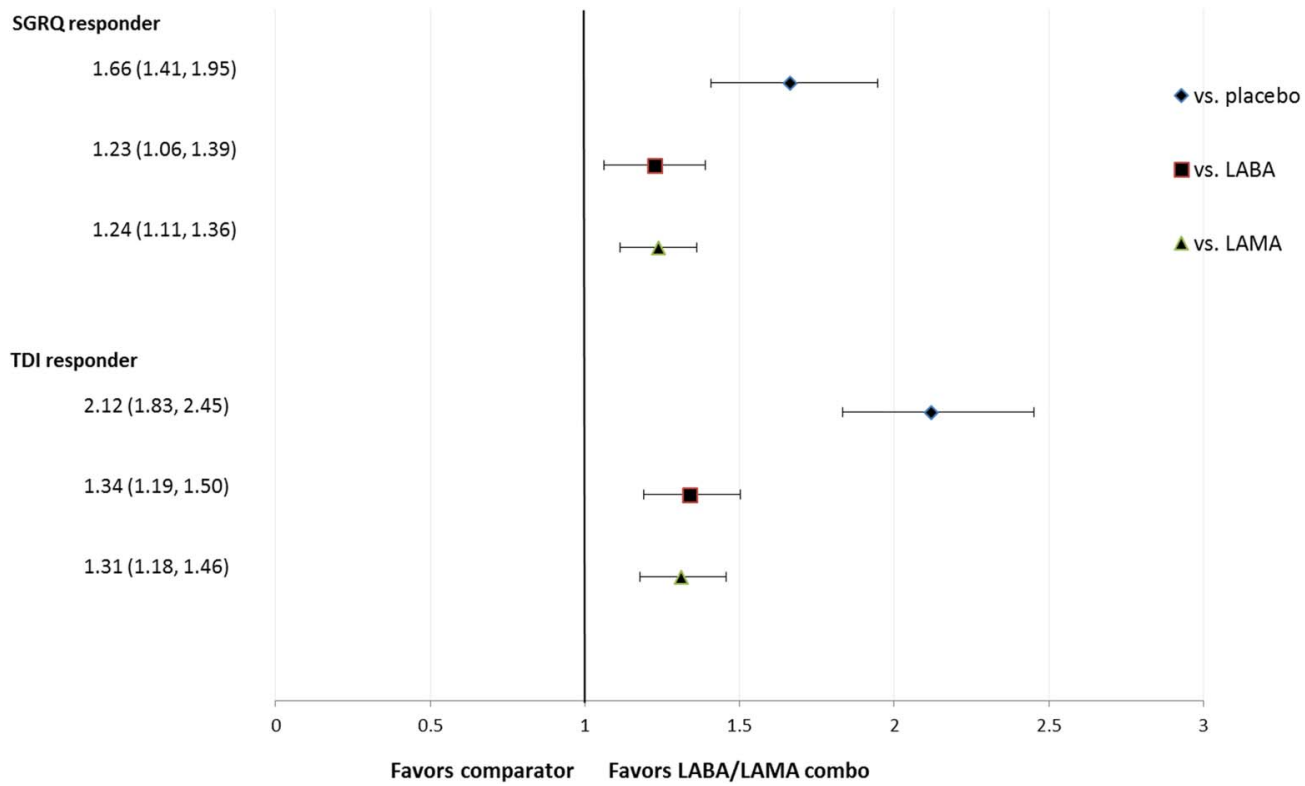

Figure 5 Summary effects of LABA/LAMA combination versus comparators on proportion of SGRQ and TDI responders at 6 months. Note: OR (95\% credible interval). A responder was defined as a subject with an improvement of at least 4 units in SGRQ total score or 1 unit in TDI score. LABA, long-acting $\beta$-agonist; LAMA, long-acting muscarinic antagonist; SGRQ, St. George's Respiratory Questionnaire; TDI, Transition Dyspnoea Index.

have influenced the study results. Second, as with all meta-analyses, we are limited by the amount of evidence that is published, consequently some of the analyses may fail to detect a true treatment effect. Our sample size calculation suggested that the assessment of severe exacerbations was significantly underpowered except for the combination versus LAMA comparison (see online supplementary table S11). Future studies enrolling patients at much higher risk for COPD exacerbations would be helpful to increase the statistical power and shed further light on the efficacy of LABA/LAMA combinations on severe exacerbations. An imbalance in study and patient characteristics across trials cannot be completely excluded as with all meta-analyses because patients are not randomised to different trials and randomisation would not hold across the set of trials used for the analysis. The results were unchanged when adjusted for study level covariates, but the risk of residual confounding bias from unknown or unmeasured effect modifiers cannot be excluded. ${ }^{43}$ However, it is unlikely that the results are substantially biased given the consistency of results between network and direct comparison meta-analyses and the purpose of our evidence synthesis is to provide an estimate, and its uncertainty, based on the current available evidence. Third, the data included in the NMA was extracted from randomised trials and the results may not be generalisable to all patients with COPD. Forth, a cost analysis was not conducted. Future studies, especially ones that compare LABA/LAMA, LABA/ICS and LABA/LAMA/ICS combinations are necessary to determine the most cost-effective treatment option.

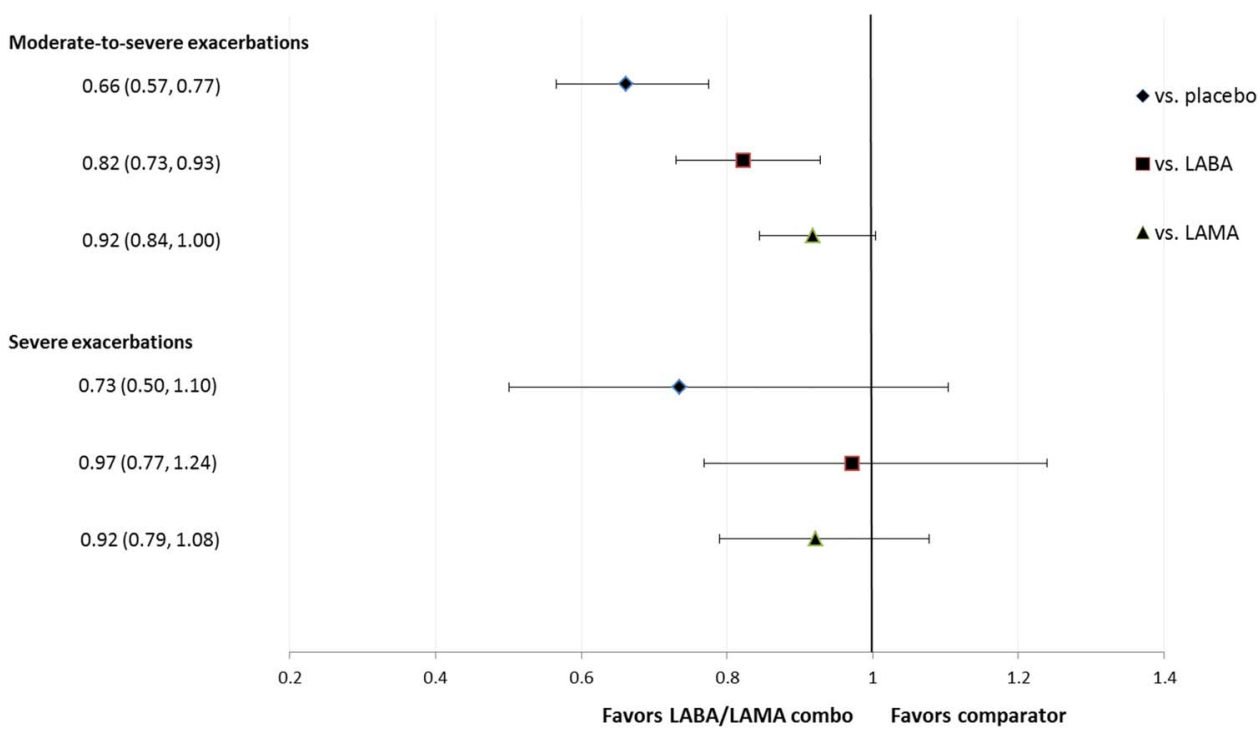

Figure 6 Summary effects of LABA/LAMA combination versus comparators on COPD exacerbations. Note: HR (95\% credible interval). LABA, long-acting $\beta$-agonist; LAMA, long-acting muscarinic antagonist. 
Table 3 Summary effects of LABA/LAMA combinations versus comparators on adverse events

\begin{tabular}{lllll}
\hline & $\begin{array}{l}\text { Mortality FE } \\
\text { HR }(95 \% \mathrm{Crl})\end{array}$ & $\begin{array}{l}\text { Total SAEs FE } \\
\text { HR (95\% Crl) }\end{array}$ & $\begin{array}{l}\text { Cardiac SAEs RE } \\
\text { HR (95\% Crl) }\end{array}$ & $\begin{array}{l}\text { Dropouts due to AE RE } \\
\text { HR (95\% Crl) }\end{array}$ \\
\hline No. of studies & 15 & 20 & 16 & 16 \\
No. of patients & 24041 & 27172 & 25913 & 23529 \\
vs placebo & $1.95(0.73,7.71)$ & $1.10(0.89,1.38)$ & $1.65(0.81,3.35)$ & $0.95(0.71,1.28)$ \\
vs LABA & $0.99(0.61,1.66)$ & $0.96(0.84,1.10)$ & $0.82(0.46,1.35)$ & $0.92(0.72,1.19)$ \\
vs LAMA & $0.87(0.64,1.16)$ & $1.04(0.95,1.14)$ & $0.87(0.59,1.27)$ & $1.03(0.84,1.26)$ \\
\hline
\end{tabular}

$A E$, adverse event; $C r l$, credible interval; $F E$, fixed-effects; LABA, long-acting $\beta$-agonist; LAMA, long-acting muscarinic antagonist; RE, random-effects; SAE, serious adverse event.

\section{CONCLUSIONS}

Our network analysis demonstrated that the combination therapy was the most effective strategy in improving lung function, quality of life, symptom scores and moderate-to-severe exacerbation rates. The combination therapy was associated with fewer moderate-to-severe exacerbations compared with LABAs, but not when compared with LAMAs. The combination therapy had similar effects on safety outcomes and severe exacerbations as compared with monotherapies. Future studies including patients with a more severe form of COPD and comparing LABA/LAMA, LABA/ICS and LABA/LAMA/ICS combinations would help healthcare practitioners and societies to better position the place of LABA/LAMA combinations in the armamentarium of COPD therapies.

Contributors YO and STS conceived the study and were responsible for the data search and extraction. SD advised on the choice of Bayesian models, created the binomial-cloglog model and conducted the analyses on exacerbation outcomes. YO produced the figures and all authors contributed to the writing of the manuscript.

Competing interests None declared.

Provenance and peer review Not commissioned; externally peer reviewed.

\section{REFERENCES}

1 World Health Organization Chronic respiratory diseases. Global surveillance, prevention and control of chronic respiratory diseases. Chronic obstructive pulmonary disease. http://www.who.int/respiratory/copd/en (accessed 12 Dec 2014)

2 Dalal AA, Christensen L, Liu F, et al. Direct costs of chronic obstructive pulmonary disease among managed care patients. Int J Chron Obstruct Pulmon Dis 2010;5:341-9.

3 Vestbo J, Hurd SS, Agustí AG, et al. Global strategy for the diagnosis, management, and prevention of chronic obstructive pulmonary disease: GOLD executive summary. Am J Respir Crit Care Med 2013;187:347-65.

4 Cazzola M, Lopez-Campos JL, Puente-Maestu L. The MABA approach: a new option to improve bronchodilator therapy. Eur Respir J 2013;42:885-7.

5 Malerba M, Morjaria JB, Radaeli A. Differential pharmacology and clinical utility of emerging combination treatments in the management of COPD-role of umeclidinium/vilanterol. Int J Chron Obstruct Pulmon Dis 2014;9:687-95.

6 Feldman GJ, Edin A. The combination of umeclidinium bromide and vilanterol in the management of chronic obstructive pulmonary disease: current evidence and future prospects. Ther Adv Respir Dis 2013;7:311-19.

7 Beeh KM. "All I want for christmas is two": the advent of novel fixed-combination inhalers for COPD and outlook for 2014. Adv Ther 2013:30:1033-7.

8 Lu G, Ades AE. Combination of direct and indirect evidence in mixed treatment comparisons. Stat Med 2004;23:3105-24.

9 Witek TJ Jr, Mahler DA. Minimal important difference of the transition dyspnoea index in a multinational clinical trial. Eur Respir J 2003;21:267-72.

10 Higgins JP, Altman DG, Gotzsche PC, et al. The Cochrane Collaboration's tool for assessing risk of bias in randomised trials. BMJ 2011;343:d5928.

11 Dias S, Sutton AJ, Ades AE, et al. Evidence synthesis for decision making 2: a generalized linear modeling framework for pairwise and network meta-analysis of randomized controlled trials. Med Decis Making 2013;33:607-17.

12 Toft N, Innocent GT, Gettinby G, et al. Assessing the convergence of Markov Chain Monte Carlo methods: an example from evaluation of diagnostic tests in absence of a gold standard. Prev Vet Med 2007;79:244-56.

13 Salanti G, Ades AE, loannidis JP. Graphical methods and numerical summaries for presenting results from multiple-treatment meta-analysis: an overview and tutorial. J Clin Epidemiol 2011;64:163-71.
14 Spiegelhalter DJ, Best NG, Carlin BP, et al. Bayesian Measures of Model Complexity and Fit. J R Stat Soc Series B Stat Methodol 2002;64:583-639.

15 Dias $S$, Welton NJ, Sutton AJ, et al. Evidence synthesis for decision making 4 : inconsistency in networks of evidence based on randomized controlled trials. Med Decis Making 2013;33:641-56.

16 Dias S, Sutton AJ, Welton NJ, et al. Evidence synthesis for decision making 3: heterogeneity--subgroups, meta-regression, bias, and bias-adjustment. Med Decis Making 2013;33:618-40.

17 Bhaumik DK, Amatya A, Normand SL, et al. Meta-Analysis of Rare Binary Adverse Event Data. J Am Stat Assoc 2012;107:555-67.

18 Thorlund K, Mills EJ. Sample size and power considerations in network meta-analysis. Syst Rev 2012;1:41.

19 Buhl R, Maltais F, Abrahams R, et al. Tiotropium and olodaterol fixed-dose combination versus mono-components in COPD (GOLD 2-4). Eur Respir J 2015;45:969-79

20 Celli B, Crater G, Kilbride S, et al. Once-daily umedidinium/vilanterol 125/25 mcg in COPD: a randomized, controlled study. Chest 2014;145:981-91.

21 Decramer $M$, Anzueto $A$, Kerwin $E$, et al. Efficacy and safety of umeclidinium plus vilanterol versus tiotropium, vilanterol, or umeclidinium monotherapies over 24 weeks in patients with chronic obstructive pulmonary disease: results from two multicentre, blinded, randomised controlled trials. Lancet Respir Med 2014;2:472-86

22 D'Urzo AD, Rennard SI, Kerwin EM, et al. Efficacy and safety of fixed-dose combinations of aclidinium bromide/formoterol fumarate: the 24-week, randomized, placebo-controlled AUGMENT COPD study. Respir Res 2014;15:123.

23 Maleki-Yazdi MR, Kaelin T, Richard N, et al. Efficacy and safety of umeclidinium/ vilanterol $62.5 / 25 \mathrm{mcg}$ and tiotropium $18 \mathrm{mcg}$ in chronic obstructive pulmonary disease: results of a 24-week, randomized, controlled trial. Respir Med 2014:108:1752-60.

24 Singh D, Jones PW, Bateman ED, et al. Efficacy and safety of aclidinium bromide/ formoterol fumarate fixed-dose combinations compared with individual components and placebo in patients with COPD (ACLIFORM-COPD): a multicentre, randomised study. BMC Pulm Med 2014;14:178

25 Vincken W, Aumann J, Chen $\mathrm{H}$, et al. Efficacy and safety of coadministration of once-daily indacaterol and glycopyrronium versus indacaterol alone in COPD patients: the GLOW6 study. Int J Chron Obstruct Pulmon Dis 2014:9:215-28.

26 ZuWallack R, Allen L, Hernandez G, et al. Efficacy and safety of combining

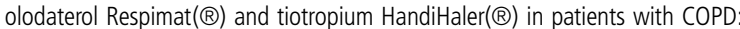
results of two randomized, double-blind, active-controlled studies. Int J Chron Obstruct Pulmon Dis 2014;9:1133-44.

27 Bateman ED, Ferguson GT, Barnes N, et al. Dual bronchodilation with QVA149 versus single bronchodilator therapy: the SHINE study. Eur Respir J 2013:42:1484-94.

28 Dahl R, Chapman KR, Rudolf $M$, et al. Safety and efficacy of dual bronchodilation with QVA149 in COPD patients: the ENLIGHTEN study. Respir Med 2013;107:1558-67.

29 Donohue JF, Maleki-Yazdi MR, Kilbride S, et al. Efficacy and safety of once-daily umeclidinium/vilanterol 62.5/25 mcg in COPD. Respir Med 2013;107:1538-46.

30 Wedzicha JA, Decramer M, Ficker JH, et al. Analysis of chronic obstructive pulmonary disease exacerbations with the dual bronchodilator QVA149 compared with glycopyrronium and tiotropium (SPARK): a randomised, double-blind, parallel-group study. Lancet Respir Med 2013;1:199-209.

31 Donohue JF, Niewoehner D, Brooks J, et al. Safety and tolerability of once-daily umeclidinium/vilanterol $125 / 25 \mathrm{mcg}$ and umeclidinium $125 \mathrm{mcg}$ in patients with chronic obstructive pulmonary disease: results from a 52-week, randomized, double-blind, placebo-controlled study. Respir Res 2014;15:78.

32 GlaxoSmithKline. An exercise endurance study to evaluate the effects of treatment of Chronic Obstructive Pulmonary Disease (COPD) patients with a dual bronchodilator: GSK573719/GW642444. Study A. 2012. http://www.gsk-clinicalstudyregister.com/ search?study_ids=DB2114417\#ps (accessed 11 Dec 2014).

33 GlaxoSmithKline. An exercise endurance study to evaluate the effects of treatment of Chronic Obstructive Pulmonary Disease (COPD) patients with a dual 
bronchodilator: GSK573719/GW642444. Study B. 2012. http://www. gsk-clinicalstudyregister.com/search?study_ids=2114418\#ps (accessed 12 Dec 2014).

34 Mahler DA, D'Urzo A, Bateman ED, et al. Concurrent use of indacaterol plus tiotropium in patients with COPD provides superior bronchodilation compared with tiotropium alone: a randomised, double-blind comparison. Thorax 2012;67:781-8.

35 Novartis A 52-week treatment, multi-center, randomized, open label, parallel group study to assess the long term safety and tolerability of QVA149 $(110 \mathrm{mcg}$ indacaterol/50 mcg glycopyrrolate 0. .d.) using tiotropium (18 mcg o.d.) as an active control in Japanese patients with moderate to severe chronic obstructive pulmonary disease (COPD). 2012. http://www.novctrd.com/ctrdWebApp/clinicaltrialrepository/ public/product.jsp?divisionld=2\&product|D $=650 \&$ diseaseArealD $=9$ (accessed 12 Dec 2014)

36 Tashkin DP, Pearle J, lezzoni D, et al. Formoterol and tiotropium compared with tiotropium alone for treatment of COPD. COPD 2009;6:17-25.

37 Vogelmeier C, Kardos P, Harari S, et al. Formoterol mono- and combination therapy with tiotropium in patients with COPD: a 6-month study. Respir Med 2008; 102:1511-20.
38 Aaron SD, Vandemheen KL, Fergusson D, et al. Tiotropium in combination with placebo, salmeterol, or fluticasone-salmeterol for treatment of chronic obstructive pulmonary disease: a randomized trial. Ann Intern Med 2007;146:545-55.

39 Brooks SP, Gelman A. Alternative methods for monitoring convergence of iterative simulations. J Comput Graph Statist 1998;7:434-55.

40 Karner C, Cates CJ. Long-acting beta(2)-agonist in addition to tiotropium versus either tiotropium or long-acting beta(2)-agonist alone for chronic obstructive pulmonary disease. Cochrane Database Syst Rev 2012;4:CD008989.

41 Oba Y, Lone N. Comparative efficacy of long-acting muscarinic antagonists in preventing COPD exacerbations: a network meta-analysis and meta-regression. Ther Adv Respir Dis 2015;9:3-15.

42 Friedman M, Serby CW, Menjoge SS, et al. Pharmacoeconomic evaluation of a combination of ipratropium plus albuterol compared with ipratropium alone and albuterol alone in COPD. Chest 1999;115:635-41.

43 Jansen JP, Trikalinos T, Cappelleri JC, et al. Indirect treatment comparison/network meta-analysis study questionnaire to assess relevance and credibility to inform health care decision making: an ISPOR-AMCP-NPC Good Practice Task Force report. Value Health 2014;17:157-73. 